\title{
Development of the Gastrointestinal Mucosal Barrier V. Comparative Effect of Calcium Binding on Microvillus Membrane Structure in Newborn and Adult Rats
}

\author{
K. Y. PANG, ${ }^{(34)}$ J. L. BRESSON, ${ }^{(33)}$ AND W. A. WALKER \\ Department of Pediatrics, Harvard Medical School and Pediatric Gastrointestinal and Nutrition Unit, \\ Massachusetts General Hospital, Boston, Massachusetts, USA
}

\begin{abstract}
Summary
Electron spin resonance (ESR) and the spin label method, with 5-doxyl stearic acid as a probe, were used to investigate the structure of microvillus membrane (MVM) from small intestine of adult and newborn rats. It was shown that the spin label in MVM of newborn was maintained in a more disordered environment than the spin label in adult animals. Calcium ion was used as an external stimulus to study the structural response and organization of these two membrane preparations. $\mathrm{Ca}^{++}$enhanced the order of 5-doxyl stearic acid labeled MVM from mature and immature rats in a concentration-dependent saturable process, but $\mathrm{Ca}^{++}$exerted a greater ordering effect on MVM from immature than MVM from the mature rat. $\mathrm{Ca}^{++}$binding to $\mathrm{MVM}$ was also a concentration-dependent, saturable process. MVM from immature rat bound significantly more $\mathrm{Ca}^{++}$in $\mathrm{CaCl}_{2}$ concentration ranges from $12.5 \mu \mathrm{m}$ to $4 \mathrm{mM}$. Scatchard analysis of the binding data showed two classes of binding sites with a high affinity constant of $3.1 \times 10^{4} \mathrm{M}^{-1}$ and a low affinity constant of $9.1 \times 10^{3} \mathrm{M}^{-1}$, with corresponding maximum binding capacities for each class site of $129.8 \mathrm{nmole}$ of calcium $/ \mathrm{mg}$ protein and $252.7 \mathrm{nmole}$ calcium $/ \mathrm{mg}$ of protein in newborn and 13-day-old MVM. Only one high affinity constant of $2.6 \times 10^{4} \mathrm{M}^{-1}$ with a corresponding maximum binding capacity of $106.4 \mathrm{nmole} / \mathrm{mg}$ of protein was observed in adult MVM. Proteolytic hydrolysis of the membranes by trypsin produced an increase in $\mathrm{Ca}^{++}$binding in adult MVM and a decrease in $\mathrm{Ca}^{++}$binding in newborn MVM. Neuraminidase and phospholipase $C$ reduced the amount of bound $\mathrm{Ca}^{++}$in both adult and newborn MVM. These results indicate a more disordered structure of newborn MVM and a differential effect of $\mathrm{Ca}^{++}$on MVM during development.
\end{abstract}

\section{Abbreviations}

ESR, electron spin resonance

G, Gauss units

MVM, microvillus membrane

The microvillus surface (glycocalyx) of the small intestine represents a highly differentiated and metabolically active compartment that contributes to the final stages of digestion and active transport of nutrients, as well as providing an important barrier to the penetration of toxic and antigenic macromolecules and pathogens present in the luminal environment (10). In previous studies, we had begun to characterize the microvillus surface of the small intestine from developing animals and to compare its barrier function with that of the adult animals. We have thus far separated differences in the glycoprotein composition of isolated MVM and binding characteristics of lectins and enterotoxins to MVM from adult and newborn intestinal mu- cosal preparations $(1,2)$. In more recent comparative studies, we determined actual structural differences in MVM preparations from small intestine of adult and newborn animals and their differential structural response to the binding of enterotoxin using a membrane probe, 5-doxyl stearic acid (22). Because calcium ion has been used successfully to study plasma membrane characteristics from liver and kidney as well as mitochondrial membranes and endoplasmic reticulum $(3,14,16,21)$, we began in this study to examine the comparative $\mathrm{Ca}^{++}$ion binding characteristics of MVM and the effect of $\mathrm{Ca}^{++}$ion binding on the structure of MVM from intestinal preparations of newborn, 13-day-old, and adult rats.

\section{MATERIALS AND METHODS}

Membrane preparation. Microvillus membranes were prepared from newborn, 13-day-old, and 6-month-old female Sprague Dawley rats (Charles River, Wilmington, MA) by a modification of the method of Schmitz et al. (25), as previously reported (22). The final membrane preparation was maintained in $10 \mathrm{mM}$ Hepes buffer, pH 7.4 for studies. Purity of membrane preparations was assessed by determining the specific activity of marker enzymes sucrase (adult) and lactase (newborn and 13-day-old) (18). The final ratio of specific activities of sucrase from the purified membrane preparation compared to the initial homogenates ranged from 13-20. The enrichment factor of lactase activity in a MVM preparation from immature animals ranged from 20-30. No DNA was detected in either of the final membrane preparations (7). Membrane protein concentration was determined by the method of Lowry et al. (15).

Measurement of membrane structure. The spin label method was used to monitor the effect of calcium ion on MVM isolated from newborn and adult rats. The spin label probe, 5-doxyl stearic acid (Sylva Co., Palo Alto, CA) at a concentration of 6.5 $\mathrm{mM}$, for labeling membranes was stored at $-20^{\circ} \mathrm{C}$ in absolute methanol. Ten to twenty microliters of spin label stock solution were dried under nitrogen gas and mixed with $500 \mu$ of MVM preparations in $10 \mathrm{mM}$ Hepes buffer, the mixture was vortexed for $1 \mathrm{~min}$ to ensure dispersion of the spin label into MVM. To study the effect of $\mathrm{Ca}^{++}$on MVM structure, $100 \mu \mathrm{l}$ of $\mathrm{CaCl}_{2}$ solution in concentrations from $0.1 \mathrm{mM}$ to $50 \mathrm{mM}$ was mixed with equal volume of spin labeled MVM. The mixture was then incubated for $30 \mathrm{~min}$ at room temperature before an ESR spectrum was obtained. ESR spectra were recorded on a Varian E-9 spectrophotometer equipped with a variable temperature accessory. All spectra were taken at $24^{\circ} \mathrm{C}$.

The flexibility of the spin label in MVM was quantitated by first measuring the hyperfine splitting parameters $2 \mathrm{~T}^{\prime}$ (parallel) and $2 \mathrm{~T}^{\prime}{ }_{\perp}$ (perpendicular) expressed in $\mathrm{G}$ units. These measurements correspond to the separation of the outer and inner 
spectral extrema, respectively, in ESR spectrum of the labeled MVM (Fig. 1), and reflect the rotational diffusion of the spin label about the molecular axis in the membrane. Both $2 \mathrm{~T}_{\|}^{\prime}$ and $2 \mathrm{~T}^{\prime}{ }_{\perp}$ were used to calculate the order parameter $\mathrm{S}^{\prime}$ according to the method of Hubbel and McConnell (11).

$$
S^{\prime}=\frac{T_{\|}^{\prime}-T_{\perp}^{\prime}}{T_{z z}-T_{x x}} \cdot \frac{a}{a^{\prime}}
$$

The order parameter $S^{\prime}$ is an index for the flexibility of the spin label in the membrane environment or more accurately, $S^{\prime}$ measures the angular deviation of the probe from its average orientation in membrane, an amplitude of its anisotropic motion. The value of $S^{\prime}$ ranges from $0-1 ; 0$ represents a completely disordered structure and 1 represents a completely ordered structure. Both $\mathrm{S}^{\prime}$ and $2 \mathrm{~T}^{\prime}$ are highly sensitive to the changes in motional environment of the spin label, and have been shown to be inversely related to the flexibility of the label in membrane; and, therefore, directly related to the order in the membrane. In some cases, where a highly immobilized probe was observed, $2 \mathrm{~T}^{\prime}$ ॥ was a good substitute for $\mathrm{S}^{\prime}$ for indexing flexibility in membrane.

$\mathrm{Ca}^{++}$binding. MVM from newborn, 13-day-old, and adult at $1 \mathrm{mg} / \mathrm{ml}$ of membrane protein in $10 \mathrm{mM}$ Hepes buffer $\mathrm{pH} 7.4$ was mixed with equal volume of $\mathrm{CaCl}_{2}$ solutions in the concentration ranges from $25 \mu \mathrm{M}$ to $8 \mathrm{mM}$ with trace amount of $\left[{ }^{45} \mathrm{CaCl}_{2}\right.$ ] (NEZ-013 New England Nuclear, Boston, MA). The mixture was incubated at room temperature for $30 \mathrm{~min}$. Aliquots $(50-100 \mu \mathrm{l})$ of the mixture were centrifuged at $30 \mathrm{psi}$ for $15 \mathrm{~min}$ at $178,000 \times g$ in a Beckman airfuge to separate the unbound $\mathrm{CaCl}_{2}$ from MVM. The radioactivity in $25 \mu \mathrm{l}$ of supernatant and $25 \mu \mathrm{l}$ of incubation mixture were measured in a scintillation counter. (Delta 300 Scintillation system, Searle Analytic Inc. Des Plaines, IL). The amount of $\left[{ }^{45} \mathrm{Ca}^{++}\right]$bound was calculated.

The nature of $\mathrm{Ca}^{++}$binding sites in the MVM was further investigated by employing specific enzymes to modify the membrane surface. One hundred micrograms of trypsin (T-0134, Sigma, St. Louis, MO); $10 \mu \mathrm{g}$ of neuraminidase (N-2133, Sigma St. Louis, MO), $50 \mu \mathrm{g}$ of phospholipase C (P-0264, Sigma, St. Louis, MO) or $100 \mu \mathrm{l}$ of buffer (control) were mixed with $0.3 \mathrm{mg}$ MVM from adult and newborn preparations in $1 \mathrm{ml}$ of $25 \mathrm{mM}$

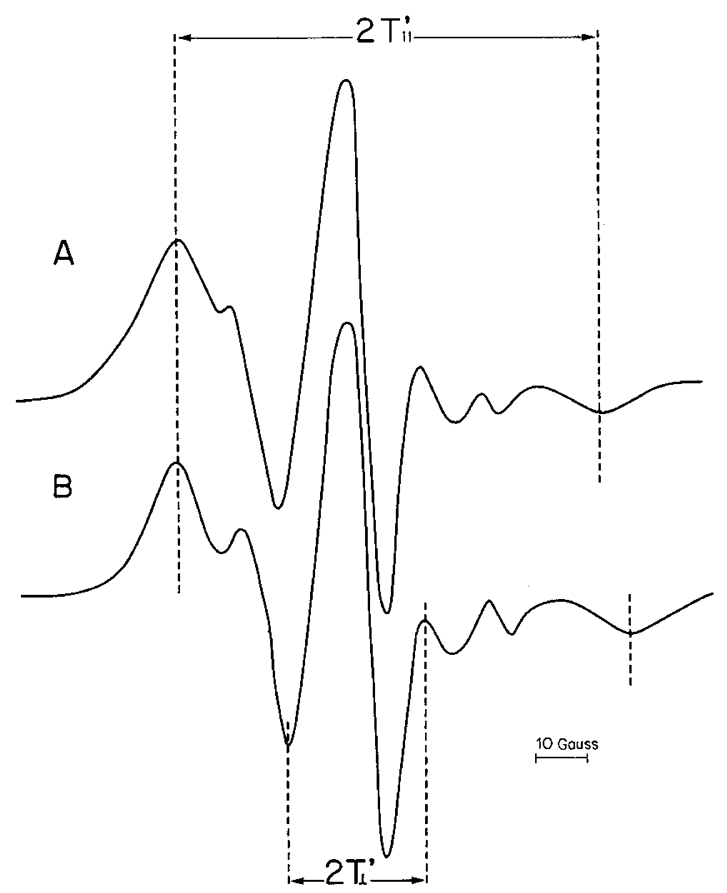

Fig. 1. A comparison of the typical electron span resonance spectrum of 5-doxyl stearic acid label newborn $(A)$ and adult $(B)$ microvillus membrane. tris butfer, $\mathrm{pH}$ 7.3. The mixture was incubated at $37^{\circ} \mathrm{C}$ for $1 \mathrm{~h}$ and centrifuged at $36,000 \times g$ for $30 \mathrm{~min}$ to separate membrane from enzyme. The precipitate was resuspended in $0.3 \mathrm{ml}$ of 10 $\mathrm{mM}$ Hepes buffer at $\mathrm{pH}$ 7.4. The treated MVM was then mixed with $0.3 \mathrm{ml}$ of $\mathrm{CaCl}_{2}$ at $50 \mu \mathrm{M}$ containing trace amount of $\left[{ }^{45} \mathrm{Ca}^{++}\right]$. Again the mixture was incubated at room temperature for 30 min and the unbound $\mathrm{Ca}^{++}$was separated from MVM by ultracentrifugation in an airfuge. The amount of $\left[{ }^{45} \mathrm{Ca}^{++}\right]$bound was calculated as previously described.

\section{RESULTS}

Microvillus membrane structure in newborn and adult animals. A comparison of representative ESR spectra of 5-doxyl stearic acid labeled MVM from adult and newborn rats at $24^{\circ} \mathrm{C}$ are shown in Figure 1. These spectra indicate that the spin label undergoes a rapid, anisotropic motion about its long molecular axis in a fairly restricted environment $(8,11)$, i.e., flexing motions of the probe are relatively restricted. In Figure 1, it is clear that $2 \Upsilon^{\prime}{ }_{\|}$in MVM from adult preparation is greater than $2 T^{\prime} \|$ in MVM from newborn preparation. Using the expression in equation (1), order parameters were found to be $0.746 \pm 0.010$ for adult MVM and $0.677 \pm 0.002$ for newborn MVM (with six membrane preparations). Both $2 \mathrm{~T}^{\prime}$ and $\mathrm{S}^{\prime}$ have been noted to be inversely related to the flexibility of the probe in membrane and therefore, related to the order of the membrane. At the same temperature, the spin probe of MVM from newborn rats reported a smaller order parameter than that of the spin probe in MVM from adult rats, suggesting a less ordered environment in MVM from newborn.

Effect of calcium on MVM structure. The effect of calcium on the MVM structure was tested by adding $\mathrm{CaCl}_{2}$ to 5-doxyl stearic acid labeled microvillus membrane at $24^{\circ} \mathrm{C}$. Millimolar $\mathrm{CaCl}_{2}$ decreased the membrane flexibility of MVM from newborn and adult, as indicated by a positive increase in $2 \mathrm{~T}^{\prime} \|$ (Fig. 2). The

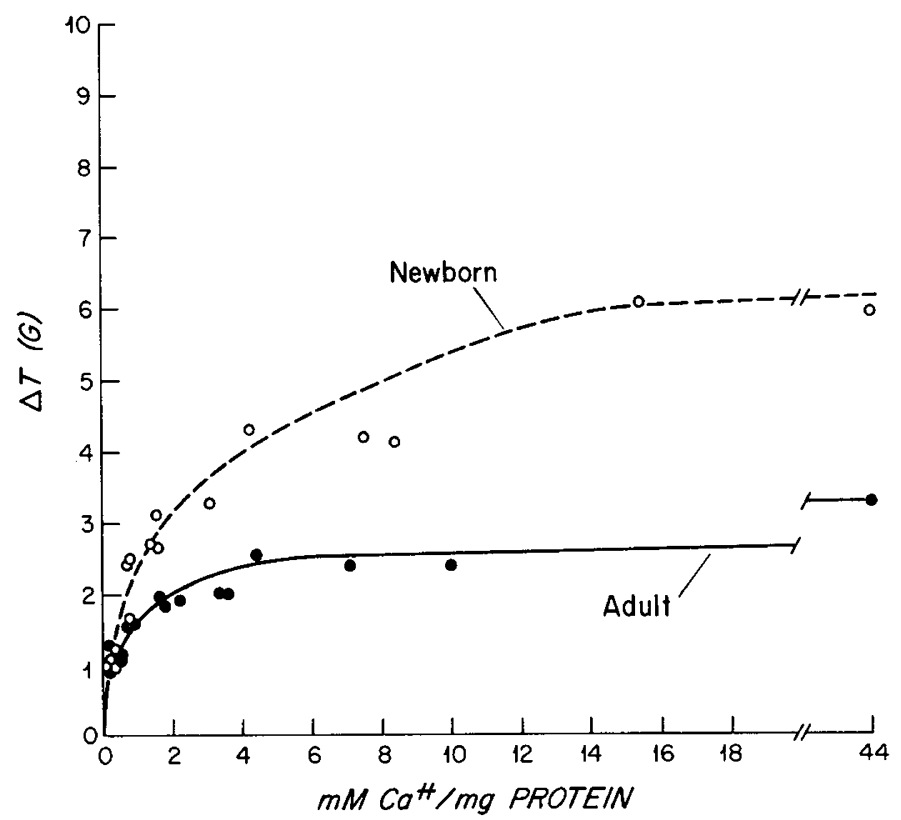

Fig. 2. Effect of increasing $\mathrm{CaCl}_{2}$ concentration on 5-doxyl stearic acid labeled microvillus membranes (MVM) from adult $(\bullet)$ and newborn (O). The experimental procedures are described in "Materials and Methods." $\Delta \mathrm{T}=\left(2 \mathrm{~T}^{\prime}{ }_{\|}\right)_{\mathrm{Ca}}^{++-}\left(2 \mathrm{~T}_{\|}^{\prime}\right)_{\mathrm{MVM}}$. Where $\left(2 \mathrm{~T}^{\prime} \|\right)_{\mathrm{Ca}}{ }^{++}$is the hyperfine splitting constant of 5-doxyl stearic acid labeled $\mathrm{MVM}$ with $\mathrm{CaCl}_{2}$ at that concentration; $\left(2 \mathrm{~T}^{\prime}{ }_{\|}\right)_{\mathrm{MVM}}$ is the hyperfine splitting constant of 5-doxyl stearic acid labeled MVM in $10 \mathrm{mM}$ hepes, $\mathrm{pH} 7.4$ without $\mathrm{CaCl}_{2}$. Membrane protein concentrations were in the range from $0.8-4.5 \mathrm{mg}$ / $\mathrm{ml}$. Spin label concentrations ranged from $1-5 \times 10^{-5} \mathrm{M}$. The mean $2 \mathrm{~T}^{\prime}$ for adult MVM is $57.85 \pm 0.39 \mathrm{G}(n=6)$ and $53.00 \pm 0.13 \mathrm{G}(n$ =6) for newborn MVM. 
calcium effect on these membranes appeared to be a concentration-dependent saturable process. There were major differences observed between the immature and mature MVM in their reactions to calcium ions. $\mathrm{Ca}^{++}$had a greater effect in ordering the MVM from immature rats than that from adult rats. The ordering effect reached a maximum at $5 \mathrm{mM} \mathrm{CaCl}_{2} / \mathrm{mg}$ of protein in adult MVM whereas no saturation was observed in MVM from newborn up to $15 \mathrm{mM} \mathrm{CaCl} / 2 / \mathrm{mg}$ of protein.

The nature of the $\mathrm{Ca}^{++}$-induced ordering in 5-doxyl stearic acid labeled MVM was characterized in additional experiments. The ordering effect of $\mathrm{CaCl}_{2}$ remained unchanged in the presence of $150 \mathrm{mM} \mathrm{NaCl}$, indicating that the action of $\mathrm{Ca}^{++}$was not due to the increase in ionic strength.

$\left.{ }^{45} \mathrm{Ca}^{++}\right]$binding to $M V M$. Next, the binding characteristic of $\mathrm{Ca}^{++}$to MVM was examined by ultracentrifugation. $\mathrm{Ca}^{++}$binding reached a steady state by $15 \mathrm{~min}$ at all concentrations studied. It was a concentration-dependent process (Fig. 3) reaching a plateau at about $200 \mu \mathrm{M}$ in adult MVM, and at about $4 \mathrm{mM}$ in 13-day-old and newborn MVM. Scatchard analysis of a typical binding study at $10 \mathrm{mM}$ Hepes $\mathrm{pH} 7.4$ after correction for nonspecific binding $(4,24)$ is shown in Figure 4 . Two classes of binding sites with a high affinity constant of $3.1 \times 10^{4} \mathrm{M}^{-1}$ and a low affinity constant of $9.1 \times 10^{3} \mathrm{M}^{-1}$ with the corresponding maximum binding capacities for each class site being 129.8 nmole of calcium $/ \mathrm{mg}$ protein and 252.7 nmole calcium $/ \mathrm{mg}$ protein in newborn and 13-day-old MVM. In contrast, only one high affinity constant of $2.6 \times 10^{4} \mathrm{M}^{-1}$ with a corresponding maximum binding capacity of $106.4 \mathrm{nmole} / \mathrm{mg}$ of protein was observed in adult MVM. There was excellent agreement among three different microvillus membrane preparations with standard errors for Bmax and $\mathrm{Ka}$ values of less than $10 \%$ of the mean values.

The $\mathrm{Ca}^{++}$binding to MVM was also carried out at high $(0.5$ $\mathrm{mM})$ and low $(0.1 \mathrm{mM}) \mathrm{CaCl}_{2}$ concentrations, with increasing amounts of MVM to further characterize the nature of the binding (Fig. 5). At low $\mathrm{CaCl}_{2}$ concentration, the amount of bound $\mathrm{Ca}^{++}$increased with greater MVM concentration and yet, no saturation effect was observed up to $2.0 \mathrm{mg} / \mathrm{ml}$ of MVM in both adult and newborn preparations; however, there was a considerably larger amount of $\mathrm{Ca}^{++}$bound to MVM from newborn than from adult animals in the entire range of MVM concentrations. Again at $0.5 \mathrm{mM} \mathrm{CaCl}$, more $\mathrm{Ca}^{++}$was bound to newborn MVM than MVM from adults, and both MVM preparations eventually reached saturation.

$\left[{ }^{45} \mathrm{Ca}^{++}\right]$binding to modified $M V M$. To determine which components in the microvillus membrane were involved in the $\mathrm{Ca}^{++}$ binding, MVM were modified with various enzymes and binding experiments repeated. Proteolytic hydrolysis of the membranes by trypsin produced a $8 \%$ increase in the amount of $\mathrm{Ca}^{++}$bound in adult MVM and $17 \%$ decrease in newborn MVM at $25 \mu \mathrm{M}$ $\mathrm{CaCl}_{2}$ (Fig. 6). These data suggested a differential effect of trypsin on these membrane preparations. Since the carboxyl group of neuraminic acid residues are possible binding sites for $\mathrm{Ca}^{++}(27)$, the effect of their removal by neuraminidase was studied. The results are shown in Figure 6 . Treatment of neuraminidase decreased $\mathrm{Ca}^{++}$binding in both adult and newborn MVM. These results suggest that neuraminic acid may play an important role in $\mathrm{Ca}^{++}$binding to MVM. Phospholipase $\mathrm{C}$ removes the entire polar group of phospholipids and would be expected to decrease the number of binding sites available to $\mathrm{Ca}^{++}(21)$. The results from phospholipase $C$ experiments (Fig. 6) show a dramatic decrease in $\mathrm{Ca}^{++}$binding in both MVM.

\section{DISCUSSION}

The microvillus surface of the small intestine represents a highly differentiated and metabolically active compartment which contributes to the end states of digestion and active transport of nutrients, as well as providing an important barrier to the penetration of toxic substances present in the external

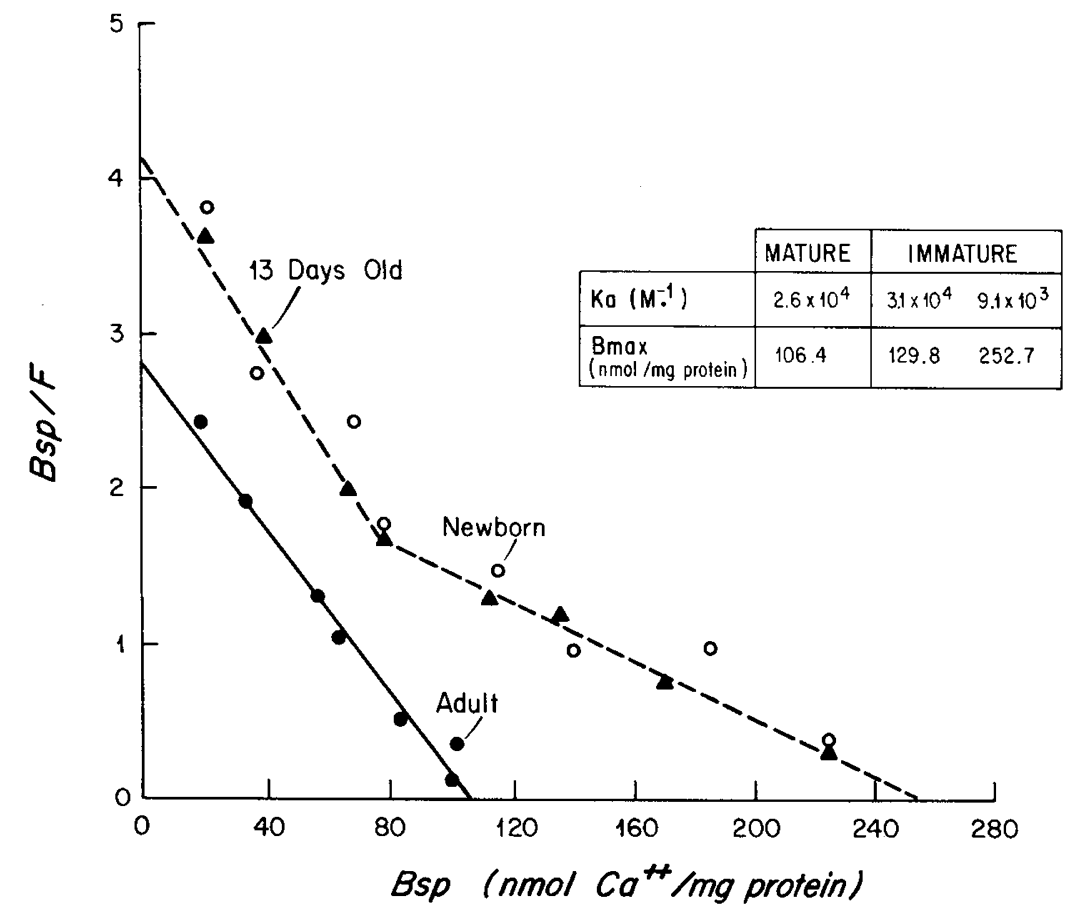

Fig. 3. Dependence of calcium chloride concentration on calcium binding to microvillus membranes, (MVM) from adult (@) to 13-day-old (A), and newborn $(\mathrm{O})$ rat small intestine. The experiments were performed as outlined in "Materials and Methods." The incubation mixture contained $0.5 \mathrm{mg} / \mathrm{ml} \mathrm{MVM}$ in $10 \mathrm{mM}$ Hepes, $\mathrm{pH} 7.4$ and varying amount of unlabeled $\mathrm{CaCl}_{2}$ in a final concentration ranging from $12.5 \mu \mathrm{M}$ to $4 \mathrm{mM}$ and a trace amount of $\left[{ }^{45} \mathrm{CaCl}_{2}\right]$. Results were obtained from three different membrane preparations with duplicate or triplicate determinations. 


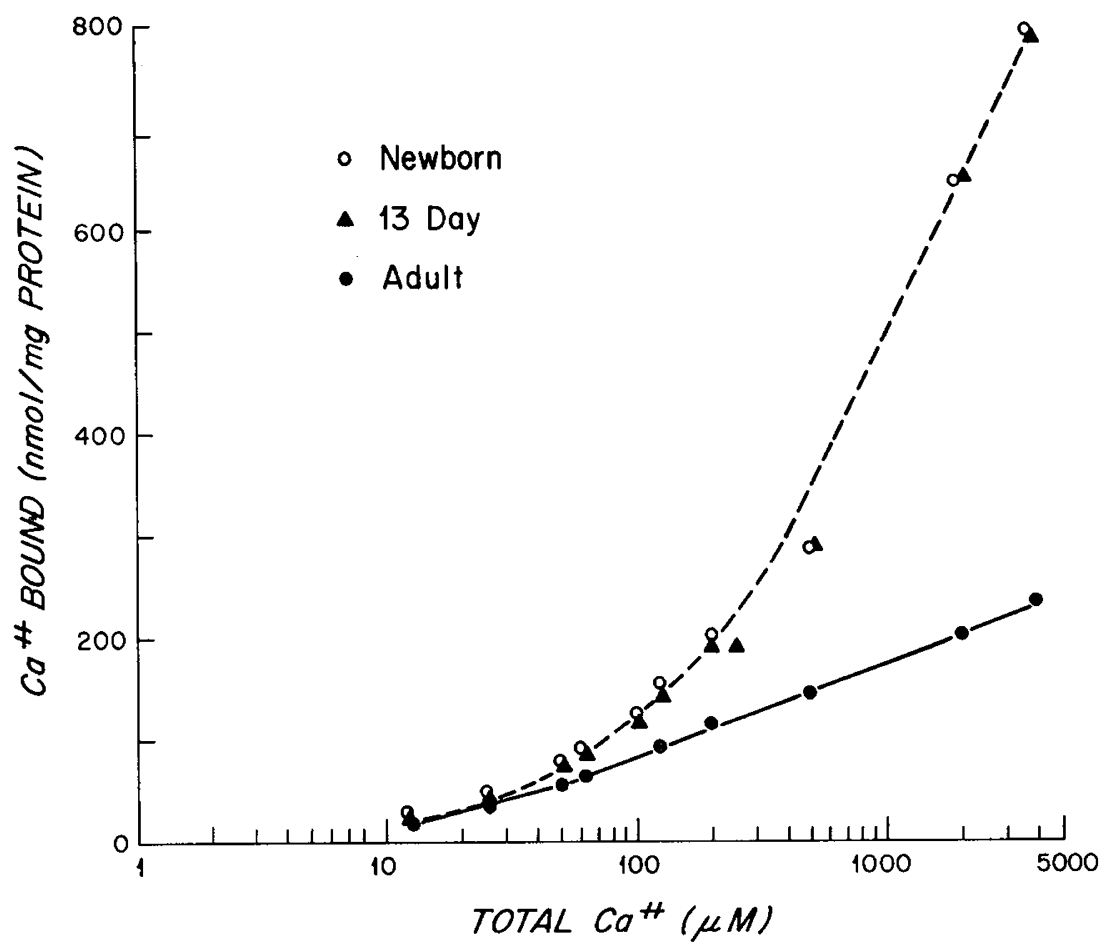

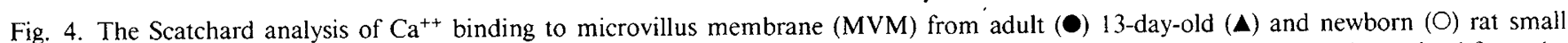
intestine. Binding data are taken from Figure 3. The affinity constant $(\mathrm{Ka})$ and the maximum binding capacity (Bmax) were determined from the slope and extrapolated $x$ intercept of each line.

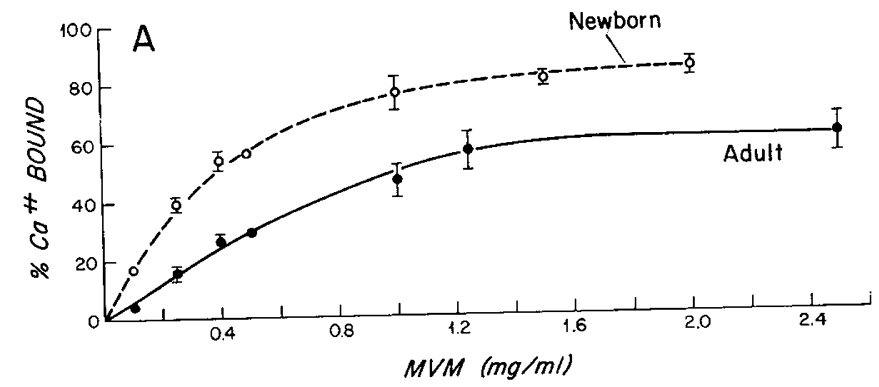

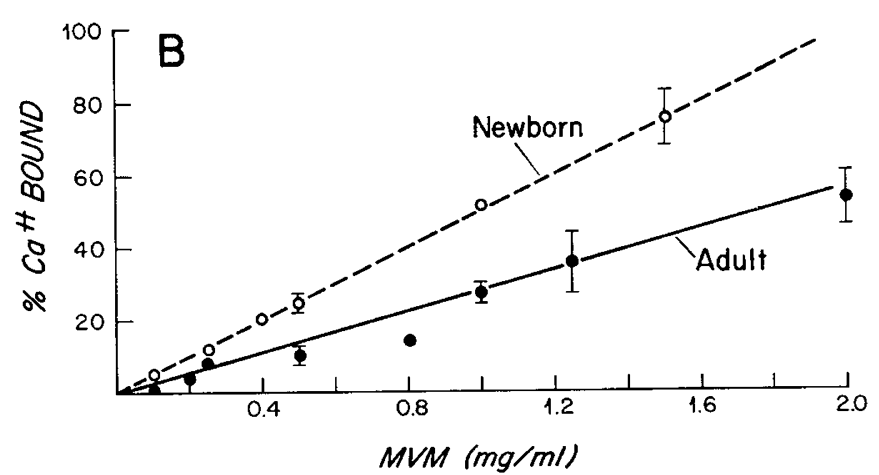

Fig. 5. Dependence of membrane concentration on calcium binding to microvillus membrane (MVM) from adult $(\bullet)$ and newborn $(O)$ rat small intestine $(A)$ at $0.1 \mathrm{mM} \mathrm{CaCl}_{2}$ and $(B)$ at $0.5 \mathrm{mM} \mathrm{CaCl}_{2}$. Experiments were carried out as follows: microvillus membrane concentration ranging from $0.1-5 \mathrm{mg} / \mathrm{ml}$ in $10 \mathrm{mM}$ Hepes, $\mathrm{pH} 7.4$ were mixed with 0.2 or $1.0 \mathrm{mM} \mathrm{CaCl}_{2}$ and a trace amount of $\left[{ }^{45} \mathrm{CaCl}_{2}\right]$. The mixture of $\mathrm{CaCl}_{2}$ and microvillus membrane was incubated at room temperature for 30 min and bound $\left[{ }^{45} \mathrm{Ca}^{++}\right]$was separated from unbound $\left[{ }^{45} \mathrm{Ca}^{++}\right]$by ultracentrifugation as described in "Materials and Methods." The \% of $\mathrm{Ca}^{++}$bound was calculated. These results are the means of four different membrane preparations with duplicate samples. Error bars are standard errors. In the cases where the standard error is smaller than the symbol; the error bar could not be seen.

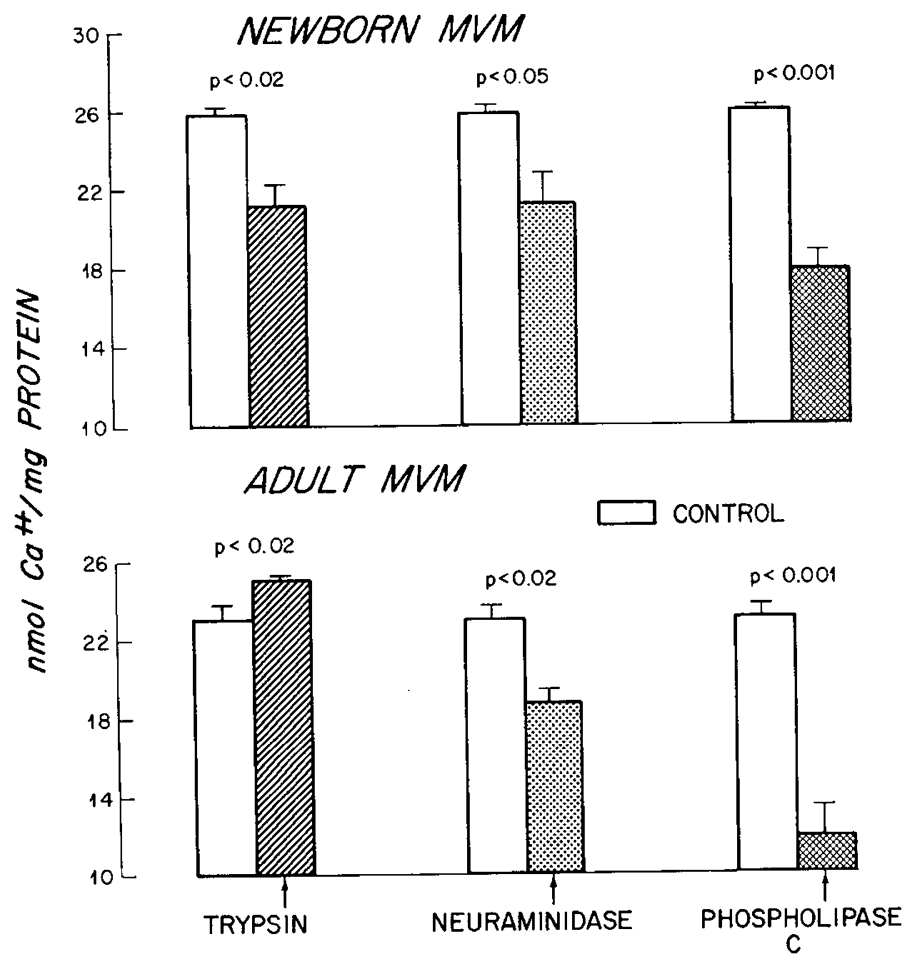

Fig. 6. Effect of trypsin, neuraminidase, and phospholipase $\mathrm{C}$ on $\mathrm{Ca}^{++}$binding to microvillus membrane from adult and newborn rat small intestine. The experiments were carried out as described in "Materials and Methods." These results are the means of three different membrane preparations with duplicate samples. Student's $t$ test is used to establish the significance between the control and the enzyme-treated membrane preparations. 
environment. We have previously reported that macromolecules are transported intracellularly by enterocytes as metabolicallyactive or antigenic molecules via a pinocytotic process involving absorption to and invagination of the microvillus surface $(5,31$, 32). In a separate study, we have shown that bovine serum albumin was transported in larger quantities across the small intestine of newborn and young rabbits compared with adults after oral ingestion of the protein $(29,30)$. More recently, studies from this laboratory have shown that microvillus membranes from immature animals are more disorganized than the MVM from mature animals (22) and the glycoprotein composition in these two membrane preparations are quite different $(1,2)$. These results strongly suggest that the differences in the mucosal barrier function in developing animals may be related to differences in MVM composition and structure. Schlatz and Marinetti (27) reported that structural integrity of rat liver plasma membrane was essential for optimal $\mathrm{Ca}^{++}$binding. Palmer and Posey $(21)$ have shown that phospholipase $\mathrm{C}$-treated renal microsomal membrane bound less $\mathrm{Ca}^{++}$than untreated membranes. These studies demonstrated the potentials of $\mathrm{Ca}^{++}$ion in probing membrane characteristics. The present study was designed to examine the effect of $\mathrm{Ca}^{++}$binding on preparation of newborn and adult MVM in order to further characterize structural differences in these two groups of animals.

Using 5-doxyl stearic acid as a standard spin label probe for isolated microvillus membranes, we were able to reproduce spectra similar to that previously reported for 5-doxyl stearic acid labeled model membranes and other biologic membranes $(6,8$, 11) (Fig. 1). In comparing MVM from adult and newborn animals, both $2 \mathrm{~T}^{\prime} \|$ and $\mathrm{S}^{\prime}$ were significantly higher than corresponding values of newborn MVM. These results strongly suggested that the spin probe in newborn MVM was maintained in a much more disordered environment than the probe in adult MVM. Similar results had been observed in MVM from adult and newborn rabbit using ESR technique (22) and fluorescence spectroscopy (26). A more disordered membrane from immature animals renders it easier for the newly synthesized protein and lipid molecules to be inserted into the fluid portion of the bilayer and after lateral diffusion take their position in the membrane (17). At the same time, a more disordered membrane is probably more vulnerable to external stimuli such as $\mathrm{Ca}^{++}$, consequently, a greater ordering effect by $\mathrm{Ca}^{++}$on immature MVM.

$\mathrm{Ca}^{++}$enhanced the order of 5-doxyl stearic acid labeled microvillus membrane from the small intestine of adult and newborn rats in a concentration-dependent, saturable manner, probably by binding to specific membrane sites. It has been previously reported that calcium ion caused ordering in model membranes as well as biologic membranes such as rat liver plasma membrane, adipocyte ghosts and lymphocyte ghosts $(13,14,23)$. This ordering effect has been associated with the regulatory role $\mathrm{Ca}^{++}$ ion played in membrane transport (Glucose, $\mathrm{Na}^{+}$) and membrane enzyme activities $(12,13,19)$. The differential ordering effect by $\mathrm{Ca}^{++}$on spin labeled adult and newborn MVM observed here suggested structural differences between mature and immature membranes. These differences in MVM may in turn alter the effect of $\mathrm{Ca}^{++}$on physiologic functions in these mature and developing animals.

The nature of these differences can in part be explained in terms of differential $\mathrm{Ca}^{++}$binding to these membranes. With an additional binding site and a greater binding capacity for $\mathrm{Ca}^{++}$ (Fig. 4), MVM from immature animals binds more calcium ions than MVM from mature animals in $\mathrm{CaCl}_{2}$ concentration ranges from $12.5-4 \mathrm{mM}$ (Fig. 2). This in turn causes a greater ordering effect observed in spin labeled immature MVM.

Because it has been shown that protein, neuraminic acid, and phospholipids played important roles in calcium binding to plasma membranes $(20,21,27)$, the nature of $\mathrm{Ca}^{++}$binding sites was further investigated in this study by using the proteolytic enzymes, neuraminidase and phospholipase C. Trypsin-treated adult MVM binds $8 \%$ more $\mathrm{Ca}^{++}$than the untreated ones, suggesting the net gain in $\mathrm{Ca}^{++}$binding components or an increase in its binding capacity after the proteolytic enzyme digestion whereas in a similarly treated newborn MVM, a $17 \%$ decrease in $\mathrm{Ca}^{++}$binding was observed indicating a loss of binding components or a decrease in its binding capacity. These results seem to indicate a differential modification of the membrane structure in MVM from adult and newborn animals after trypsin treatment. The greater amount of $\mathrm{Ca}^{++}$binding to the unmodified membrane and the net decrease in $\mathrm{Ca}^{++}$binding to trypsin-treated membrane imply that the $\mathrm{Ca}^{++}$binding components-proteins, phospholipids, and neuraminic acids-are more superficially located on the surface of the immature MVM than that in mature MVM, and therefore more vulnerable to $\mathrm{Ca}^{++}$ion and enzymatic modification. These explanations are consistent with findings reported from our laboratory and others that there is a higher lipid to protein ratio in newborn MVM compared to adult MVM $(1,23,28)$. These results suggest a fundamental difference in organization in mature and immature MVM.

Neuraminidase removes the carboxyl groups of neuraminic acid on the surface of membrane. Microvillus membranes from both preparations treated with neuraminidase showed a decrease in $\mathrm{Ca}^{++}$binding to MVM. The effect of a polar group in membrane phospholipids on $\mathrm{Ca}^{++}$binding was examined by using phospholipase C. Phospholipase C-treated MVM from both preparations also showed a significant decrease in $\mathrm{Ca}^{++}$binding, suggesting an important role the polar group in phospholipids played in $\mathrm{Ca}^{++}$binding.

We reported here a differential ordering effect of $\mathrm{Ca}^{++}$ion on mature and immature MVM from rat small intestine. This effect is probably the result of the presence of an additional binding site and a greater maximum binding capacity of newborn MVM. In addition to polar phospholipids and neuraminic acid, calcium also probably binds to protein components on the surface of MVM from newborn. Results from this study suggest that MVM from immature rats was structurally more disordered and more vulnerable to an external stimulus like $\mathrm{Ca}^{++}$ions. These fundamental differences in MVM organization could account for many physiologic phenomenon such as increased attachment and penetration of macromolecules (29) and increased uptake of calcium ion noted during the perinatal period (9).

\section{REFERENCES AND NOTES}

1. Bresson, J. L., Pang, K., Udall, J., Fritze, L., and Walker, W. A.: Evidence for increased enterotoxin binding to newborn microvillus membranes: A possible explanation for enhanced toxigenic diarrhea in infancy. Gastroenterology, 78: 1145 (1980).

2. Bresson. J. L., Hereovics, A., and Walker, W. A.: Differences in microvillus membrane fucosylation with age and differentiation. Gastroenterology. 82 1021 (1982)

3. Carofoli, E., Gazzotti, P., Vasington. F. D.. Sattocasa, G. L., Sandri, G., Panfili, E.. and deBernard, B.: In: Biochemistry and Biophysics of mitochondrial membrane. Eds: Azzone, G. F., Garafoli. E., Lehninger, A. L., Quagliarello, E., and Siliprandi, N. pp. 623-640 (Academic Press, N.Y. 1972).

4. Chamnese, G. C. and McGuire, W. L.: Schatchard Plots: common errors in correction and interpretation. Steroids, 26: 338 (1975).

5. Cornell, R., Walker, W. A., and Isselbacher, K. J.: Small intestinal absorption of horseradish peroxidase: a cytochemical study. Lab Invest. 25: 42 (1971).

6. Gaffney, B. G.: Spin-label measurements in membrane. In: S. Fleischer and L. Packer: Methods in Enzymology. p. 161 (Academic Press, NY 1974).

7. Giles. K. J. and Myer, A.: An improved diphenylamine method for the estimation of deoxyribose nucleic acid. Nature, 206:93 (1965).

8. Griffith, O. H. and Jost, P. C.: "Spin labeling" Berliner, L. Ed.: pp. 414-523 (Academic Press. NY 1976).

9. Grishan, F. K.. Jenkins, J. T., and Younoszai, M. R.: Maturation of calcium transport in the rat small and large intestine. J. Nutr. I10:1622 (1980).

10. Henning. S. J.: Post natal development: Coordination of feeding, digestion and metabolism. Am. J. Physiol, 241: 199 (1981).

11. Hubbell, W. L. and McConnell. H. M.: Molecular motion in spin labeled phospholipids and membrane. J. Am. Chem. Soc., 93: 314 (1971).

12. Ikemoto, $\mathrm{N}$.: The calcium binding sites involved in the regulation of the purified adenosine triphosphatase of the sacroplasmic reticulum. J. Biol. Chem.. 249: 649 (1974)

13. Keefe. E. B.. Zcharschnidt, B. F., Blankenship, N. M., and Ockner, R. K. Studies of relationships among bile flow, liver plasma membrane $\mathrm{Na}, \mathrm{K}$ ATPase and membrane microviscosity in the rat. J. Clin. Invest., 64: 1590 (1979)

14. Livingston. C. J. and Schachter, D.: Lipid dynamics and lipid-protein interactions in rat hepatocyte plasma membrane. J. Biol. Chem., 255: 10902 (1980). 
15. Lowry, O. H., Rosebrough, N. J., Farr, A. L and Randall, R. G.: Protein measurement with the folin phenol reagent. J. Biol. Chem., 193: 265 (1951).

16. McDonald, N. M., Bruns, D. E., and Jarett, L.: Characterization of calcium binding to adipocyte plasma membrane. J. Biol Chem., 25I:1354 (1976).

17. Melcher, D. L. and Steim, J. M.: Thermotropic transitions in biomembranes. Ann. Rev. Biophys. Bioeng., 5: 205 (1976).

18. Messer, M. and Dahlquist, A.: A one step ultramicromethod for the assay of intestinal dissacharidases. Anal. Biochem., 14: 376 (1966).

19. Nicholson, G. L., Poste, G., and The, J.: Dynamic aspects of cell surface organization. Ed: G. Poste and G. Nicholson. pp. 1-73 (North Holland, Amsterdam 1971).

20. Nuston, C., Pangborn, W., Nir, Z., and Papadjopoulos, D.: Specificity of $\mathrm{Ca}^{++}$ and $\mathrm{Mg}^{++}$binding to phosphatidyl serine vesicles and resultant phase changes of biliary in membrane structure. Biochem. Biophys. Acta, 506: 281 (1978).

21. Palmer, R. F. and Posey, V. A.: Calcium and adenosine triphosphate binding to renal membranes. J. Gen. Physiol., 55: 89 (1970).

22. Pang, K. Y. Bresson, J. L., and Walker, W. A.: Development of the gastrointestinal barrier III. Evidence for structural differences in microvillus membrane from newborn and adult rabbits. Biochim. Biophys. Acta, 727: 201 (1983).

23. Sauerheber, R. D., Lewis, U. J., Esgate, G. A., and Gordon, L. M.: Effect of calcium insulin and growth hormone on membrane fluidity. A spin label study of rat adipocyte and human erythrocyte ghosts. Biochem. Biophys. Acta, 597: 294 (1980).

24. Scatchard, G.: Attractions of proteins for small molecules and ions. Ann. N. Y. Acad. Sci.. 51: 660 (1949).

25. Schmitz, G., Preizer, H., Malstracci, D., Ghost, B. K., Cerda, J. G., and Crane, R. K.: Purification of the human intestinal brush border membrane. Biochim. Biophys. Acta, 323: 98 (1973).

26. Schwarz, S. M., Hostetler, B., Ling, E., Lel, L., and Walkins, G. B.: Fluorescence polarization studies of the small intestinal microvillus membrane during development. Gastroenterology, 82: 1176 (1982).

27. Schlatz, L. and Marinetti, G. V.: Calcium binding to the rat liver plasma membrane. Biochim. Biophys. Acta, 290: 70 (1972).

28. Tsuboi, K. K., Schwartz, S. M., Burrill, P. H., Kwong. L. K., and Sunshine, P.: Sugar hydrolysis of the infant rat intestine and their arrangement of the brush border membrane. Biochim. Biophys. Acta, 554: 234 (1979).

29. Udall, N. J. Pang, K. Fritze, L. Kleinman, R and Walker, W. A.: Development of gastrointestinal mucosal barrier. I. The effect of age on intestinal permeability to macromolecules. Pediat. Res., 15: 241 (1981).

30. Udall, J. N., Colony, P., Fritze, L., Pang, K., Trier, J. S. and Walker, W. A.: Development of gastrointestinal mucosal barrier. The effect of natural versus artificial feedings on intestinal permeability to macromolecules. Pediatr. Res., 15: 245 (1981).

31. Walker, W. A., Cornell, R., Davenport, L. M. and Isselbacher, K. G.: Macromolecules absorption: Mechanism of horseradish peroxidase uptake and transport in adult and neonatal rat intestine. J. Cell Biol., 54: 195 (1972).

32. Warshaw, A. L., Walker, W. A., Cornell, R. and Isselbacher, K. J.: Small intestine permeability to macromolecules: Transmission of horseradish peroxidase into mesenteric lympyh and portal blood. Lab. Invest., 26: 675 (1971).

33. Current address: Department de Pediatrie, Hopital des Enfants Malades, Paris, France.

34. Received for publication Dr. Kam-Yee Pang, Pediatric Gastrointestinal and Nutrition Unit, Massachusetts General Hospital, Boston, MA 02114.

35. Supported by research grants from the National Institute of Health (AM16269. HD12437 and GM21700) Dr. Pang is a trainee in Gastrointestinal Research (T32-AM0791)

36. Received for publication August 26, 1982.

37. Accepted for publication March 23, 1983.

\title{
The Diagnosis and Staging of Hypocortisolism in Progressing Autoimmune Adrenalitis
}

\author{
SEPPO LEISTI, ${ }^{(32)}$ PEKKA AHONEN, AND JAAKKO PERHEENTUPA
}

The Children's Hospital, University of Helsinki, Helsinki, Finland

\section{Summary}

The course of development of hypocortisolism was studied in 20 patients with autoimmune polyendocrinopathy-candidosis-ectodermal dystrophy (APECED) for 1.3-9.3 years during which time the patients underwent at least three 2-h ACTH tests ( $2 \mathrm{hAT})$. A slow progression of the disease was evident and could be staged. The earliest indicators of incipient failure were subnormality of the 2-h cortisol level alone or with subnormality of the 2-h increment. The increment was then abolished. A normal basal level was maintained longer. Longer forms of the ACTH tests produced normal responses even after the early stages of failure. A constantly elevated ACTH concentration and low cortisol/ACTH ratio in plasma were likewise signs of advanced hypocortisolism. Current criteria of primary hypocortisolism are thus indicators of the late stages of failure only. The presence of circulating adrenocortical antibodies is predictive of hypocortisolism. Some patients had normal $2 \mathrm{hAT}$ responses, but antibodies and subnormal cortisol/ACTH ratios. This may represent a state of compensatory activation of the hypothalamic-pituitaryadrenocortical axis.

\section{Abbreviations}

APECED, autoimmune polyendocrinopathy-candidosis-ectodermal dystrophy
4dAT, 4-day ACTH test 2hAT, 2-h ACTH test 17-OGS, 17 oxogenic steroids RIA, radioimmunoassay

Autoimmune adrenalitis is a major cause of Addison's disease. In patients with polyendocrine deficiency diseases and their siblings, frequent testing of cortisol reserve is essential for early detection of failure of cortisol secretory capacity. Long lasting ACTH tests are impractícal, because they entail hospitalization. Furthermore, such tests may not be sensitive enough to detect incipient failure. To our knowledge, no systematic study has appeared on the progression of hypocortisolism in adrenalitis. Neither have criteria been established for early stages of primary hypocortisolism. Such criteria would be important for the safety of individuals at risk. We have used an ambulatory 2-h ACTH test (2hAT) (13) for both detection and follow-up of progression of hypocortisolism in our large series of patients with APECED $(18,23)$. The $2 \mathrm{hAT}$ was clearly more sensitive than the $4 \mathrm{dAT}$ for the detection of incipient failure and even more sensitive than determinations of plasma ACTH. Our experience with these patients calls for a revision of the current diagnostic criteria of Addison's disease. 